\title{
Laboratory research on the influence of selected technological parameters on cutting forces during hard rock mining with asymmetric disc tools
}

\author{
Grzegorz STOPKA ${ }^{1^{*}}$
}

Authors' affiliations and addresses: ${ }^{1}$ AGH University of Science and Technology, Department of Machinery Engineering and Transport, A. Mickiewicza Av. 30, 30-059

Krakow, Poland

e-mail: stopka@agh.edu.pl

*Correspondence:

Grzegorz Stopka, AGH University of Science and Technology, Department of Machinery Engineering and Transport, A. Mickiewicza Av. 30, 30-059 Krakow, Poland

e-mail: stopka@agh.edu.pl

Funding information:

AGH University of Science and Technology, Faculty of Mechanical Engineering and Robotics

How to cite this article:

Stopka, G. (2020). Laboratory research on the influence of selected technological parameters on cutting forces during hard rock mining with asymmetric disc tools. Acta Montanistica

Slovaca, Volume 25 (1), 94-104

DOI:

https://doi.org/10.46544/AMS.v25i1.9

\begin{abstract}
One of the most prospective developments of hard rock mechanical excavation methods is the possibility of the disc tools usage in new constructions of mining machinery. For many years, such research on the excavation using both symmetrical and asymmetrical disc tools has been conducted in the Department of Mining, Dressing and Transporting Machines in the AGH University in Cracow. The primary effect of these tests is an innovative solution of a mining head with complex motion trajectory asymmetrical disc tools. The concept of the disc head assumes the mining of rock stone by chipping as a result of a complex trajectory of disc tools. To develop such innovative construction of roadheader head, determination of work principles and guidelines based on laboratory tests was necessary. The article presents the methodology, course, and results of the disc tools mining tests. Those studies included quasi-static and dynamic experiments of excavation using disc tools. In this paper constructions of specially prepared laboratory stands for the examination of disc tools of complex trajectory were presented. Each trial has been performed for different physical properties of rock samples and different excavation technology. The conducted research significantly broadens the scope of knowledge in the field of mining with asymmetrical disc tools. The results of tests described in the paper could be used in the construction of innovative machines and devices for mechanical hard rock mining, in opposition to classical mining methods involving explosive materials.
\end{abstract}

\section{Keywords}

disc tools, hard rock mining, undercutting, roadheader

( $) 2020$ by the authors. Submitted for possible open access publication under the terms and conditions of the Creative Commons Attribution (CC BY) license (http://creativecommons.org/licenses/by/4.0/). 


\section{Introduction}

Rock excavation using disc tools is one of the most promising directions for the development of mechanical hard rock mining. The use of disc tools for this purpose allows, compared to the standard milling method, reducing the energy consumption of the mining process and leads to the reduction of dust generation associated with mining. The fragmentation of rock output is also reduced. Due to the significant reduction of friction forces in the rock mining process, the durability of the tools also increases. Two basic techniques of mechanical rock mining can be distinguished by means of disc tools, namely excavation with static pressure and by undercutting. The above advantages of using disc tools, especially in the case of mining hard rocks, resulted that the interest in the industrial application of the rear undercutting technique has recently increased. Attempts are made to apply disc tools not only on conceptual (prototype) machines but also in industrial ones that have used the standard mining tools (picks, teeth) (Acaroglu et al., 2017; Asbury et al., 1998; Manfred, 2005; Gospodarczyk et al., 2015a; Kotwica et al., 2003). However, this type of actions requires the use of proven calculation procedures to verify the reliability of such new solutions for mining systems.

The essence of destroying the cohesion of rocks by disc tool in a simplified way can be illustrated using the example of penetration of the wedge profile into rock half-space. A characteristic feature of this process is the relatively small size of the so-called compression zone, and therefore the foremost part of the excavated material during the disc mining is the volume of side fragments. The course of penetration of the wedge profile into a half-space is characterized by dynamic variability, which directly affects the value of the $\mathrm{P}_{\mathrm{d}}$ pressing force during mining. The consequence of this fact is the difficulty of formulating a full mathematical description of the process of disc's blade penetration into the rock body. In connection with the above, models specifying the mining resistance forces assume simplifications and allow only for an approximate estimation of forces acting on the tool during rock excavation. It should be emphasized that the computational models of different authors are most often the result of their experimental research, and so they are valid in the area of restrictions that were considered during the experiment. Also, the analytical formulas for describing the resistance forces of disc mining assume simple kinematics of the mining system (most often rectilinear). The use of analytical formulas for calculation of disc tool loads is often insufficient, and it is possible to generate errors when defining boundary conditions for new and innovative types of mining machinery (Stopka, 2011).

The dominant group of disc mining models is the one describing the load of symmetric disc tools. A standard feature of these models is the assumption of proportionality of forces generated on the disc's blade during operation to the size of the surface area of the imprint. An example of such a model is the description proposed by Roxborough and Philips (Roxborough, 1975). According to this model (Fig.1), the pressing force $\mathrm{P}_{\mathrm{d}}$ is described by the formula:

$$
P_{d}=4 \cdot 10^{-3} \cdot R_{C} \cdot \operatorname{tg} \beta \cdot \sqrt{D \cdot h^{3}-h^{4}}
$$

Where:

$R_{c}$ - uniaxial compression rock strength (UCS),

$h$ - cutting depth of the disc,

$D, \beta$-geometric parameters of the disc.

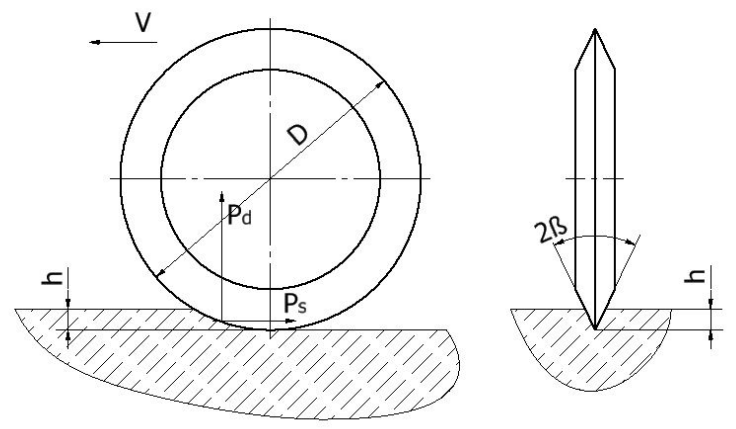

Fig.1. Diagram of forces affecting disc tool (Roxborough, 1975)

The assumption described above which characterizes the symmetrical disc mining models is a reasonable approximation of the symmetrical discs mining process in the case of simple mining kinematics (mining with static pressure). A different situation occurs in the case of the undercutting technique, where the disc moves on a complex track, and the asymmetric disc during penetration into the rock body and at the time of complete dehiscence of the rock fragment generates strongly variable lateral forces. In the case of the undercutting technique, a significant problem is the lack of a model basis allowing to predict loads of asymmetrical disc tools, 
which in effect makes the correct selection of construction parameters of mining machines difficult. The estimation of loads of specific disc tools is most often performed empirically, assuming simplified mining kinematics (Kotwica et al., 2010; Kotwica, 2011). The inadequacy of analytical methods is the reason why simulation methods have been used to analyze such problems (Gajewski et al., 2008; Gospodarczyk et al., 2015b; Jonak et al., 2012; Labra et al., 2017; Rojek, 2007; Xiaohuo et al., 2012, Xia et al., 2017).

Currently, many research and development centres attempt to use asymmetrical disc tools in the working bodies of mobile mining machines. The issues of modelling and research of prototype mining machinery solutions are one of the primary research directions implemented at the Department of Mining, Dressing and Transport Machines at AGH in Krakow, Poland (Bołoz, 2013) (Bołoz et al., 2018) (Gospodarczyk et al., 2015a). An example of this type of work is an attempt to develop and implement a new generation of disc head dedicated for use in the construction of roadheaders (Gospodarczyk et al., 2013; Gospodarczyk et al., 2016; Mendyka, 2016). The concept of the disc head assumes the mining of rock stone by chipping as a result of a complex trajectory of disc tools, presented in Figs. 2 and 3. The elaborated mining unit consists of independently propelled body and mounted in it propelled discs with asymmetrical disc tools. The unit body 1 is propelled by an external drive shaft 2 . In the body, in seats 3 drive shafts 6 are mounted with plates 4 , on which in bearing seats 10 disc tools 5 are installed. The most favourable number of tools should be 6 to 8 pieces. The drive shafts 6 are propelled by an internal drive shaft 7 independent from the external drive shaft 2 and a set of bevel gears 8 and 9 or alternative ones.

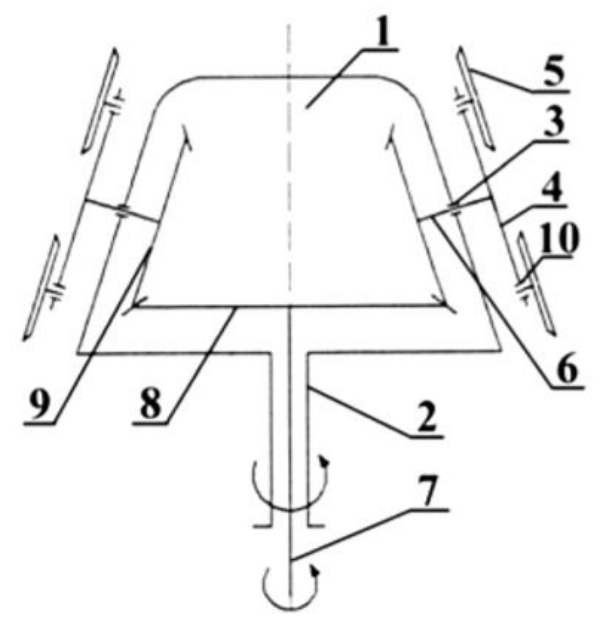

Fig.2. The conception of a unit equipped with disc tools of a complex motion trajectory

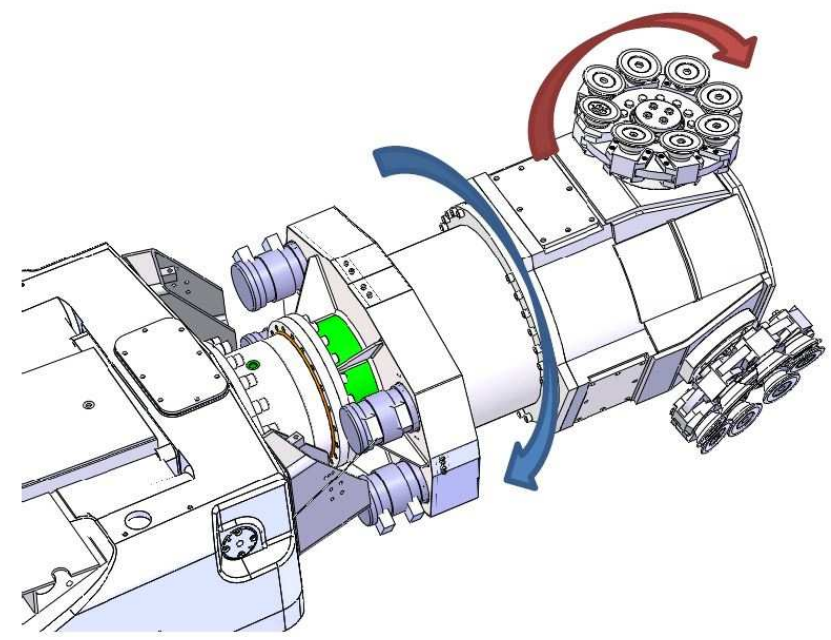

Fig.3. 3D model of the new head solution

Due to the lack of theoretical and experimental basis that would allow defining boundary conditions for the construction of a new disc head, it was decided to carry out laboratory research on asymmetrical disc tools. The primary goal of this research was to identify the impact of geometric parameters of discs and selected mining process parameters on the value of resistance forces during mining using a single disc tool and disc plate. 


\section{Testing methodology}

Research on the mining process with asymmetrical disc tools has been divided into two phases. As part of the first issue, research was conducted on the impact of geometric parameters of disc tools on the values of loads generated by pushing a tool into a rock sample. The second research problem was the assessment of the impact of selected mining process parameters, i.e., the penetration depth and cut spacing on loads of a single disc in the similar to real working conditions.

Static tests consisted of pushing the disc into a rock at a given distance from the sample edge until the material was detached entirely (Fig. 4). The following geometric and process parameters were adopted as independent variables for the tests:

- the diameter and a tip angle of the disc tool $(D, \alpha)$,

- cut spacing $(t)$,

- physical and mechanical properties of the rock sample $\left(R_{c}\right)$ (Biały, 2013; Biały, 2014).

Based on the literature analysis of the subject as well as previous author experiences in the field of industrial application of disc tools, it has been determined that the tests will be carried out for disc tools with $D=$ 150, 160 and $170 \mathrm{~mm}$ diameter and blade angles $\alpha=35^{\circ}, 40^{\circ}$, and $45^{\circ}$. Fig. 5 shows disc tools used for pressing (rock penetration) tests. During the conducted research, the $P_{d}$ pressure force and displacement of the disc tool were measured and recorded.
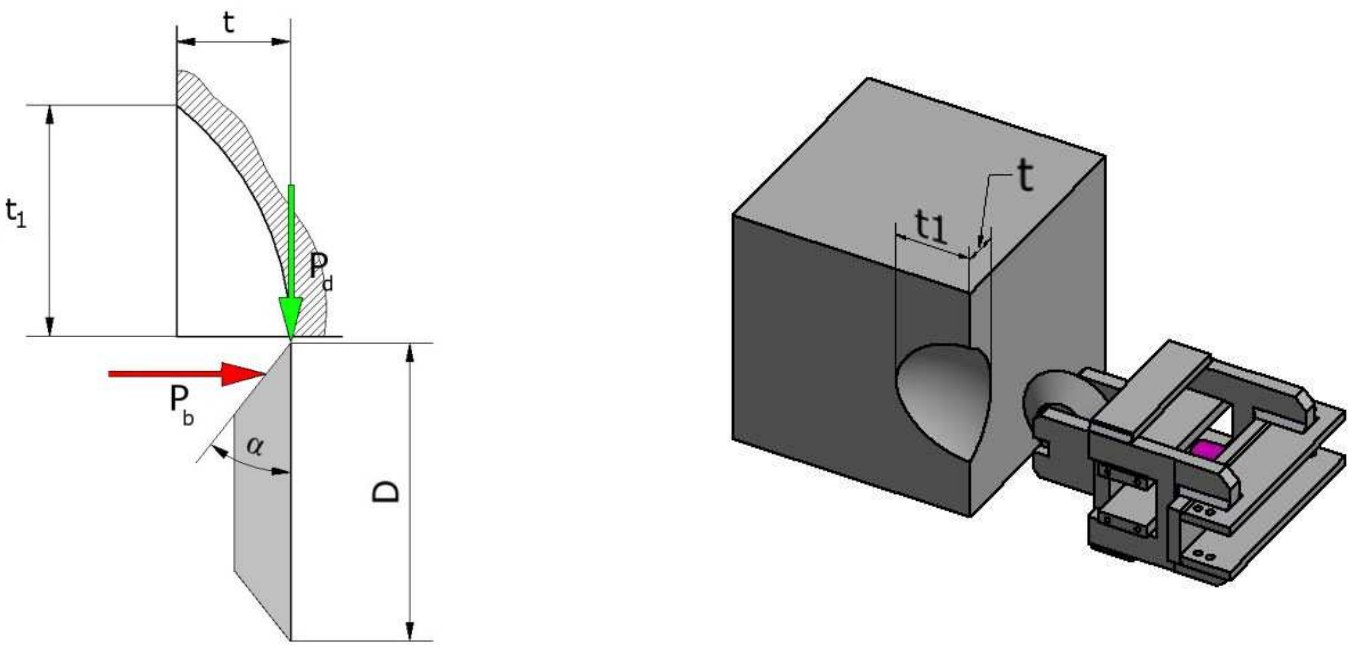

Fig.4. Measured parameters during mining tests with single disc tool

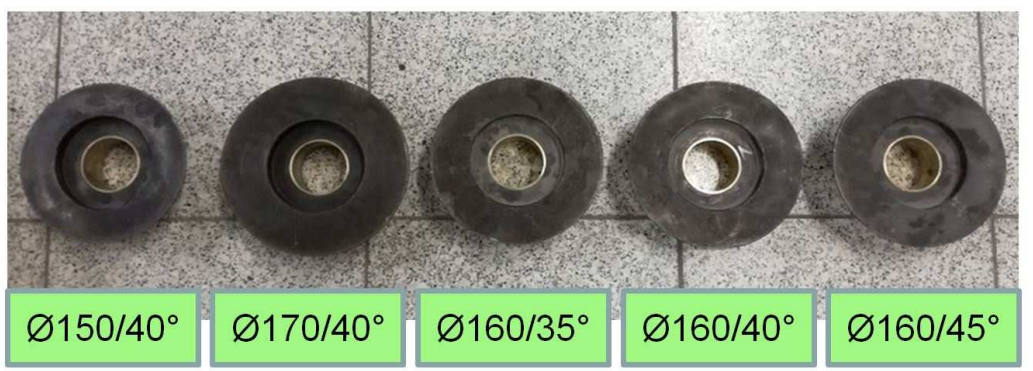

Fig.5. Tested disc tools

As part of the second phase of the research, mining tests using a plate armed with six-disc tools were performed (Fig. 6). Those tests were conducted for one type of disc geometry. Individual excavation attempts consisted of a series of cuts in the vertical plane with a given cutting depth and spacing. To reduce the number of independent variables, the measurements were made at the constant values of the plate rotational velocity and its feed rate $(v p)$, established during the pilot tests. The individual components of the cutting resistance forces $\left(P_{d}\right.$, $P_{s}$ ) were indirectly identified on the basis of pressure values in the feed cylinder of the stand and the disc plate hydraulic drive. The physical model of the disc plate load and the method of carrying out the tests are shown in the figure below. 


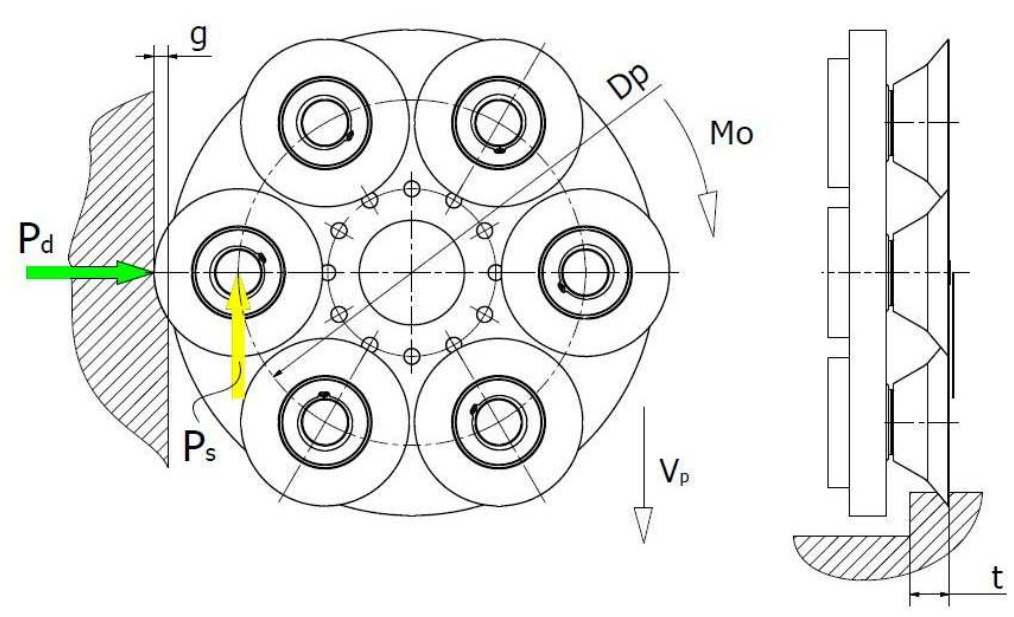

Fig.6. Diagram of vertical mining of the sample by the plate with disc tools

Research on the disc mining process was performed for concrete samples with different mechanical properties. The research with a single disc tool was carried out on concrete samples with uniaxial compressive strength of $25 \mathrm{MPa}$ and sandstone samples with uniaxial compressive strength of $79 \mathrm{MPa}$. However, disc plate mining tests were performed on a concrete sample with compressive strength $R_{c}=25 \mathrm{MPa}$. Laboratory tests were carried out on a dedicated laboratory stand, which consists of two primary components (modules). These modules are shown in Figs. 7 and 8. Each operation on the stand is carried out using hydraulic actuators (cylinders or motors). Fig. 5 shows a measuring system for testing the static process of pressing disc tools into a rock sample. Presented stand allows to attach the disc tool in the holder; the construction of this holder permits to change the position of the disc relative to the sample, and thus gives the opportunity to set the right cut spacing. The system is equipped with a strain gauge force sensor that allows measuring the pressure force in the range of $0 \div 200 \mathrm{kN}$ and a transformer displacement sensor with a measuring range of $0 \div 300 \mathrm{~mm}$. The disc tool is pressed through the feed system of the station into a rock sample in the form of a $400 \times 400 \times 400 \mathrm{~mm}$ block. The sample is fastened to the construction of the station using a special metal frame. The second module is the disc plate arm, mounted on a movable table (Fig. 8). The design of this module is described in detail in several publications (Kotwica et al., 2010). The displacement of the disc plate in the horizontal and vertical plane is due to two hydraulic cylinders. An additional movement is the table feed, along with the arm and disc plate. The angular displacement of the arm allows the plate to mine an artificial rock specimen measuring $1650 \mathrm{~mm} \times 1200$ $\mathrm{mm} \times 1000 \mathrm{~mm}\left(\sim 2 \mathrm{~m}^{3}\right)$. The tests used a disc with a pitch diameter $D_{p}=444 \mathrm{~mm}$. The drive unit of the disc is the OMTS 250 hydraulic motor by Sauer Danfoss and the RR5 / OMC planetary gear. The used disc plate drive allows obtaining the nominal torque of $3650 \mathrm{Nm}$.

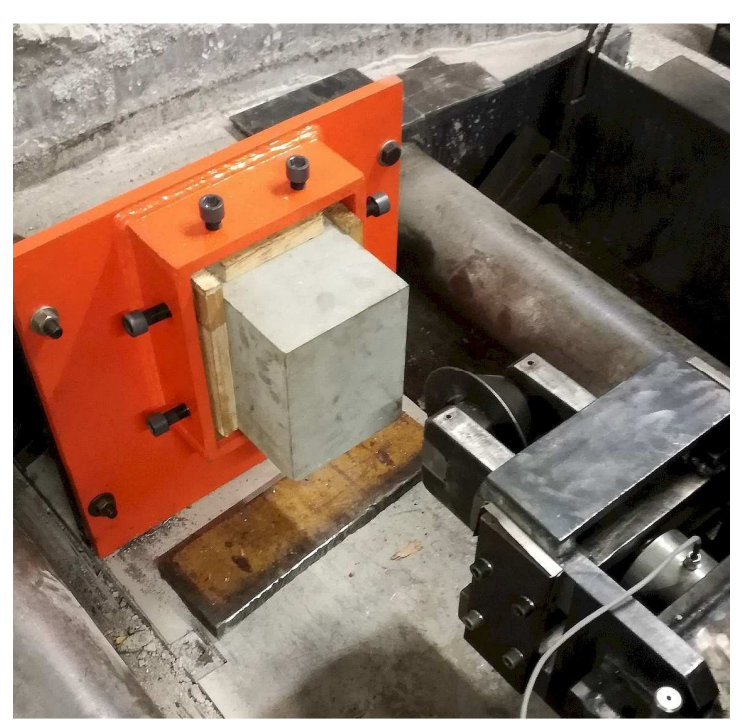

Fig.7. Lab stand for testing mining process of single disc tools

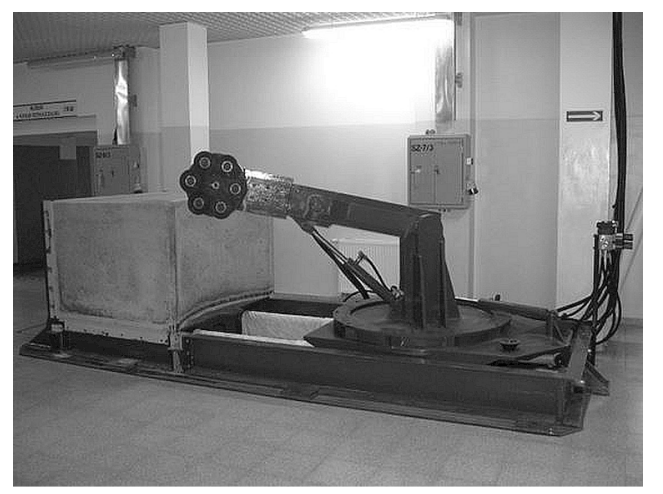

Fig.8. Lab stand for testing mining process of the plate with disc tools 


\section{Laboratory tests}

The first stage of the research was a series of tests of disc tools static insertion into samples made of concrete with different uniaxial compression strength. Each of the mining tests consisted of setting an appropriate cut spacing by the appropriate aligning and locking of the handle together with the disc tool. In the next step, the disc insertion was made close to the edge of the rectangular rock sample until the material was entirely de-bonded. The tests were carried out for three cut spacing values, namely for the parameter $t$ (Fig. 4) equal to 15,25 and $35 \mathrm{~mm}$. After each of the tests, the extent of the destruction zone was measured. Performing another attempt required moving the holder towards the opposite, intact edge of the sample and rotating the disc tool so that the cutting was obtained by the conical surface of the disc. Each of the trials for a given configuration of the geometric disc parameters and the determined scale pitch was repeated at least three times. Based on the observations made during the tests, there was a negligible share of the compression zone in the process of destroying the consistency of the sample. The vast majority of tests were completed by chip separation, whose dimensions (height, depth) were multiple times higher of the assumed cut spacing.

Exemplary results of static insertion of disc tools are presented in the following figures. Fig. 9 shows exemplary forms of destruction of samples mined with disc tools $150 \mathrm{~mm}$ in diameter. In contrast, Fig. 10 shows a form of spoil being the result of mining discs with diameters $\varnothing 160$ and $170 \mathrm{~mm}$ for different graduations.

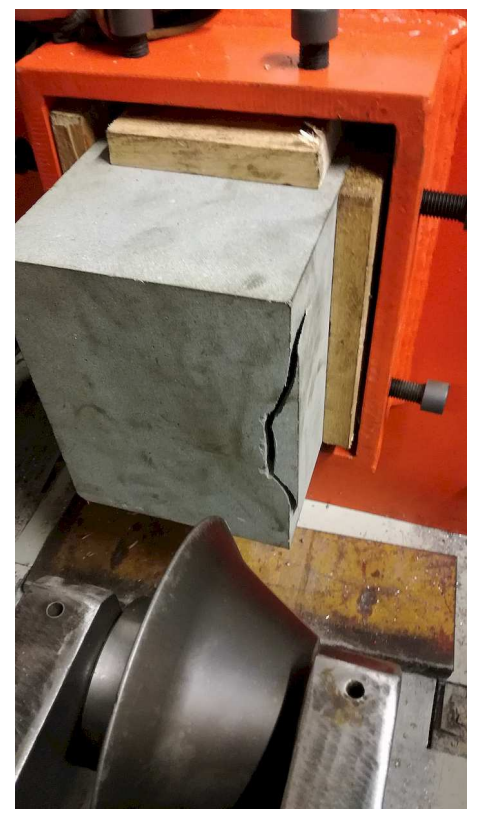

Fig.9. A view of the sandstone block after the mining test $\left(R_{c}=79 \mathrm{MPa}\right)-\operatorname{disc} \emptyset 150 / 40^{\circ}, t=15 \mathrm{~mm}$

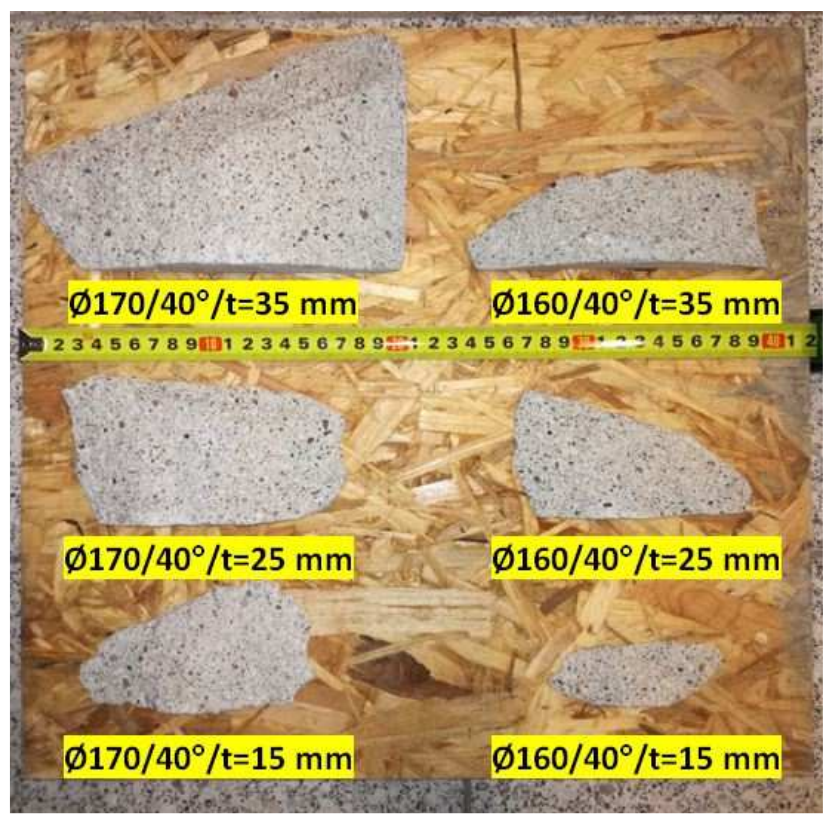

Fig.10. Graining of the output obtained during the mining tests with single disc tool $\left(R_{c}=25 \mathrm{MPa}\right)$

The second part or research included mining tests with disc plate. The test was, in a sense, analogous to the static pressing one and consisted of the task of setting an appropriate cutting depth and spacing of disc plate mining and then performing the vertical cutting. Specification of the above parameters of the mining process was carried out by appropriate positioning of the arm and table of the station using hydraulic cylinders. As in the case of static tests, the detachment of the sample material followed the conical surface of the disc. As a result of preliminary pilot tests, kinematic parameters of the disc plate during the mining process were determined. It has been assumed that the tests will be carried out for the disc plate rotational speed of $60 \mathrm{rpm}$. It was the minimum value of this parameter which allowed to carry out the mining process in a smooth way. On the basis of pilot tests, it was assumed that individual mining attempt would be carried out for a depth of cut of $g=15,20$ and 25 $\mathrm{mm}$ and a cut spacing $t=20,30,40$ and $60 \mathrm{~mm}$. As a result of the tests, it was observed that in the case of the $t=$ $60 \mathrm{~mm}$ scale the sample material was not completely crushed. For the remaining mining scales, a full exploration of the sample material was obtained for the full range of cutting depth. The form of output obtained in individual samples was characterized by a large number of platelet grains. This form of output testifies to the relatively low energy consumption of the mining process. Exemplary results of disc plate excavation research are shown in the figures below. Fig. 11 shows the moment of making the cut by plate disc, while in Fig. 12 the concrete block surface after a few series of mining tests was presented. 


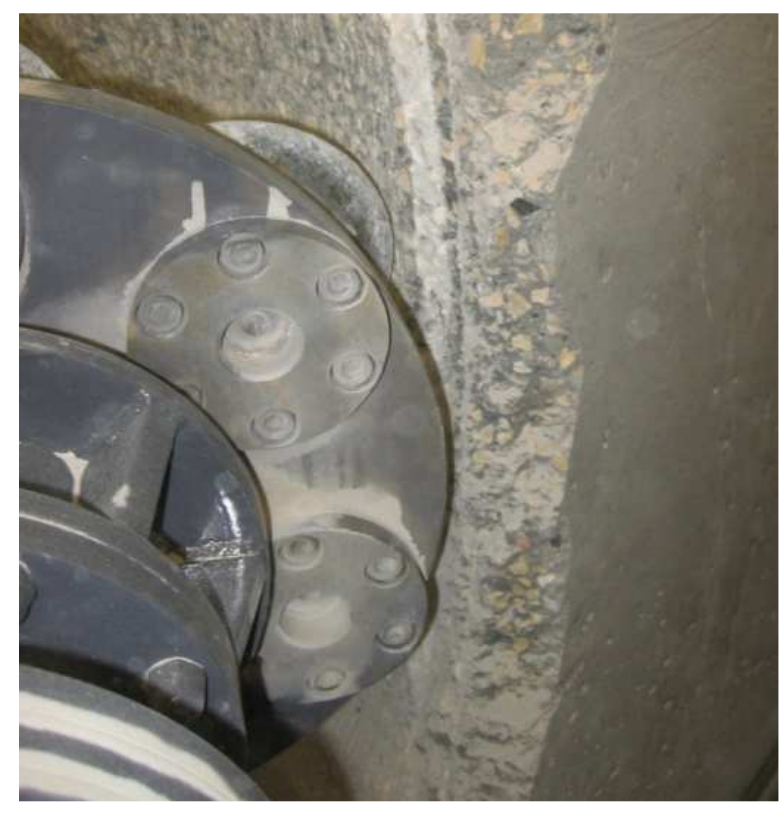

Fig.11. A view of the cut after one of the mining test

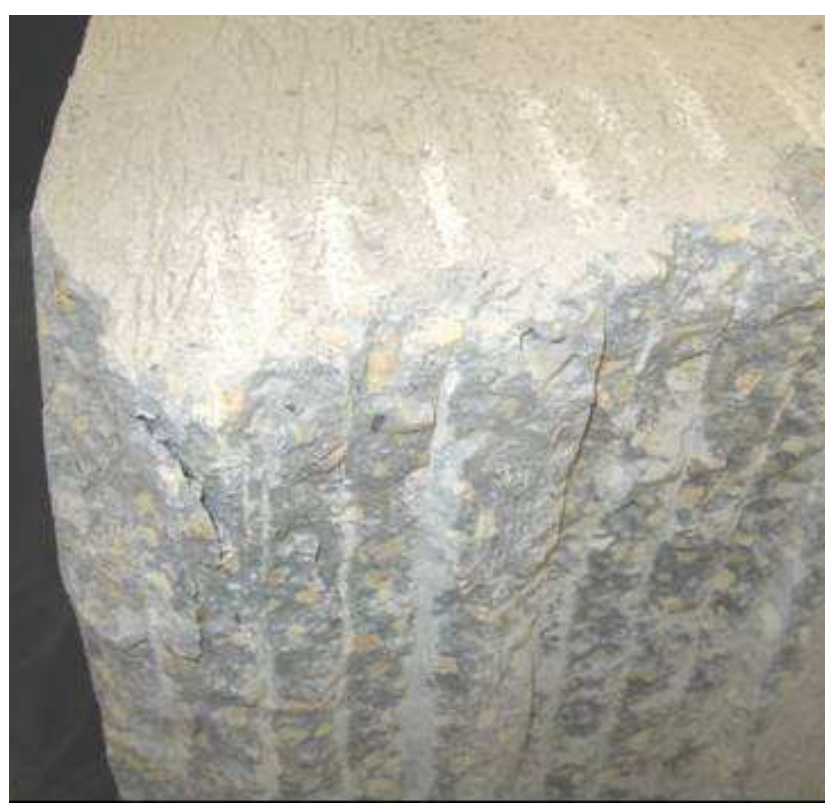

Fig.12. A view of the concrete block surface after completing the mining test

\section{Test results}

The laboratory tests allowed to identify the impact of geometrical parameters of disc tools, as well as cutting process parameters on the resistance forces of both a single disc tool and plate disc. Due to the limited number of tests carried out in this publication, only exemplary research results are provided. Static attempts to push the disc tool made it possible to quantitatively compare the influence of a number of geometric parameters of the discs on the value of the pressure force. Fig. 13 shows selected force waveforms for various configurations of process parameters and physical properties of rock samples for disc $150 \mathrm{~mm}$. The recorded waveforms are characterized by the variability typical for the processes of rock centre destruction by a tool similar in profile to the wedge. Relevant information is not only the value of the maximum destructive force but also the limit value of the disc's depth. Depending on the configuration of the geometric parameters tested, and the properties of the sample, the disc penetration causing the sample to be destroyed was 2 to $10 \mathrm{~mm}$.

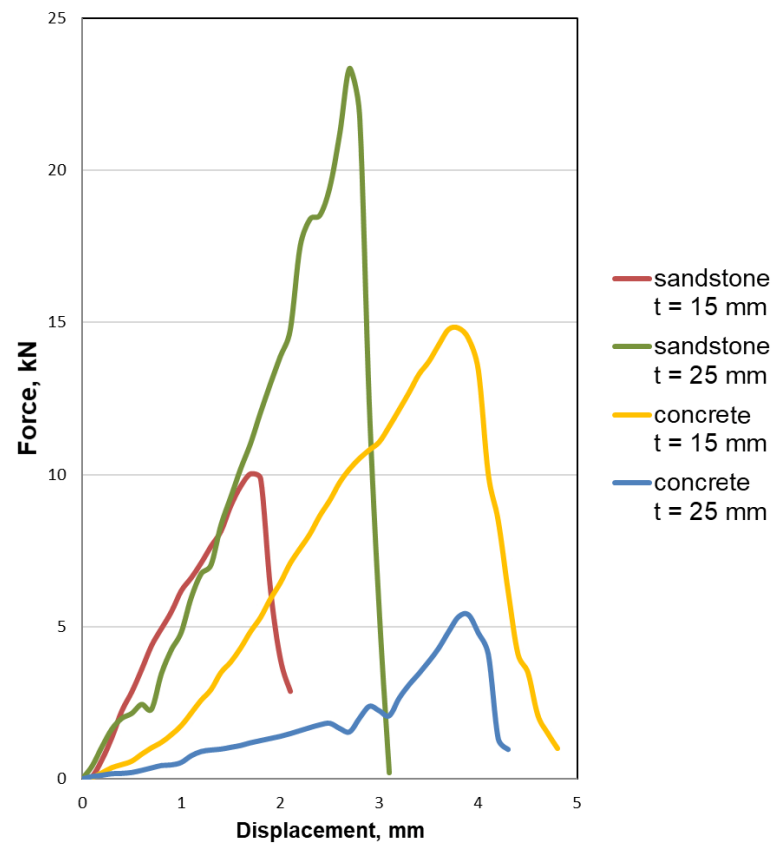

Fig.13. Exemplary courses of press force as a function of displacement for disc $\phi 150 \mathrm{~mm}$ 
Fig. 14 $\div 17$ are examples of graphs of the impact of selected geometric parameters of disc tools and cutting spacing on the value of press force. Mean values of maximum press forces were calculated on the basis of at least three measurements. Based on the results of the research, it can be concluded that the increase in the value of individual independent variables caused an increase in the generated downforce. On the other hand, the dynamics of the changes of the press forces values varied depending on the variable adopted as the input parameter for the tests. The most significant increases in the pressing force were observed in relation to the cutting spacing. The change of such parameters as the diameter of the disc or the angle of the disc's blade caused a smaller increase of the pressure force as in the case of the cutting spacing. As part of the research, the influence of the strength of the sample on the value of the pressing force of the disc tool was also checked. On the basis of the tests carried out, it can be concluded that the increase in the strength of the sample caused a proportional increase in the registered press force.

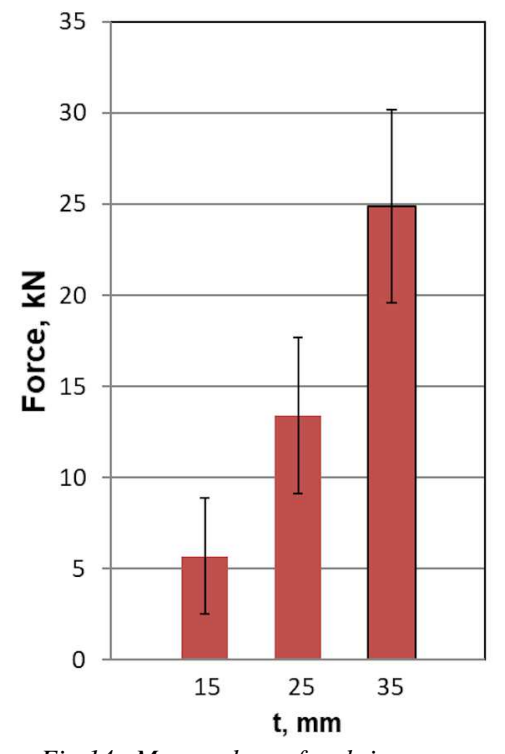

Fig.14. Mean values of maksimum press forces $\left(D=160 \mathrm{~mm}, R_{c}=25 \mathrm{MPa}\right)$

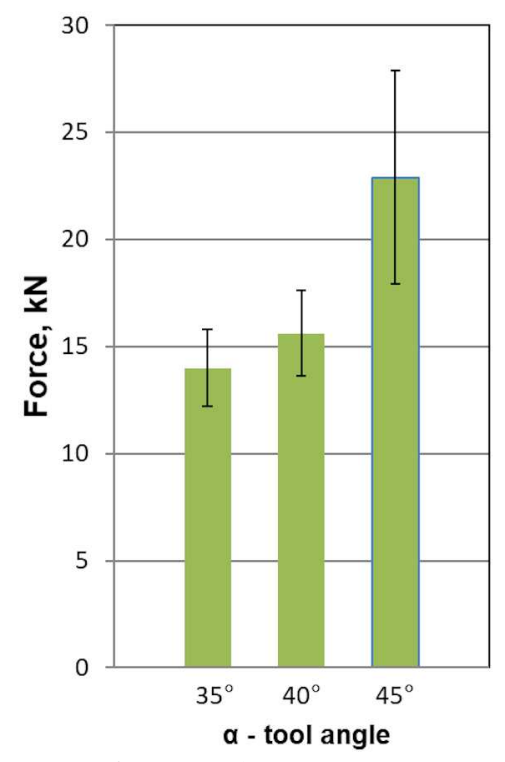

Fig.16. Mean values of maximum press forces $\left(D=160 \mathrm{~mm} t=25 \mathrm{~mm}, R_{c}=25 \mathrm{MPa}\right)$

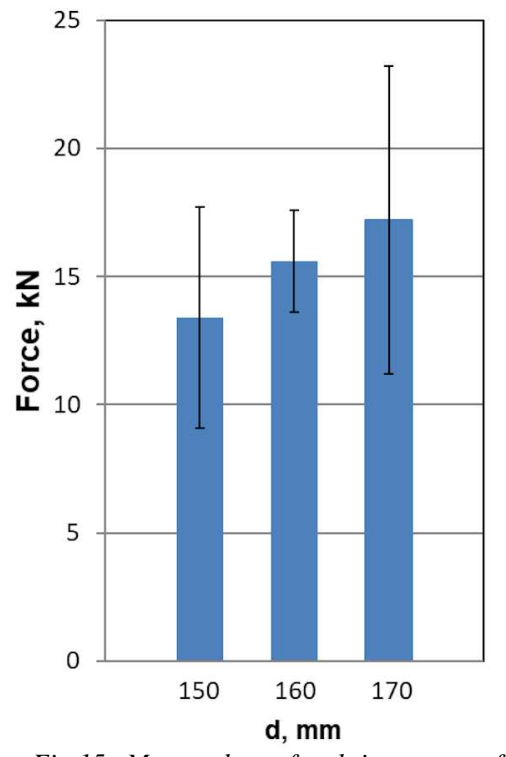

Fig.15. Mean values of maksimum press forces $\left(t=25 \mathrm{~mm}, \alpha=40^{\circ}, R_{c}=25 \mathrm{MPa}\right)$

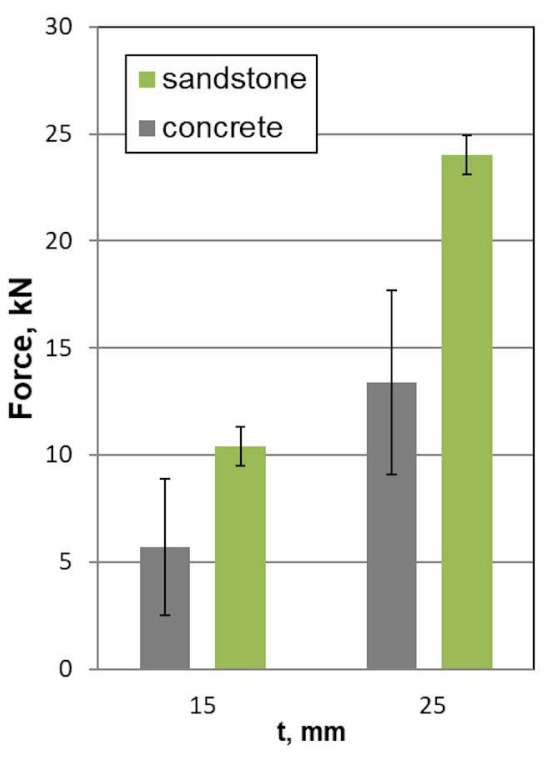

Fig.17. Mean values of maximum press forces $\left(\mathrm{D}=150 \mathrm{~mm}, R_{c}=25\right.$ and $\left.79 \mathrm{MPa}\right)$

In the second phase of research, disc plate mining tests were carried out, equipped with discs of a diameter of $160 \mathrm{~mm}$ and a $40^{\circ}$ blade angle. Fig. 18 shows an example measurement of a dynamic torque on the shaft of a disc drive motor for one of the mining tests. Based on the momentary force waveforms in the feed cylinders and the torque on the drive shaft of the disc plate drive, the average values of the individual components of the cutting resistance force were calculated for each of the tests. The exemplary test results are shown in Fig. 19 and 20. The charts show both data in a discrete form (average value) and approximations of the test results using 
curves. The conducted disc mining excavation research shows that the dominant component of the resistance force for the disc plate is the pressing force. The conducted research allowed to identify the influence of depth and cutting spacing on the value of press force and cutting disc plate. In the case of cutting force (tangential to the disc), it should be stated that the value of this force is determined primarily by the cutting depth.

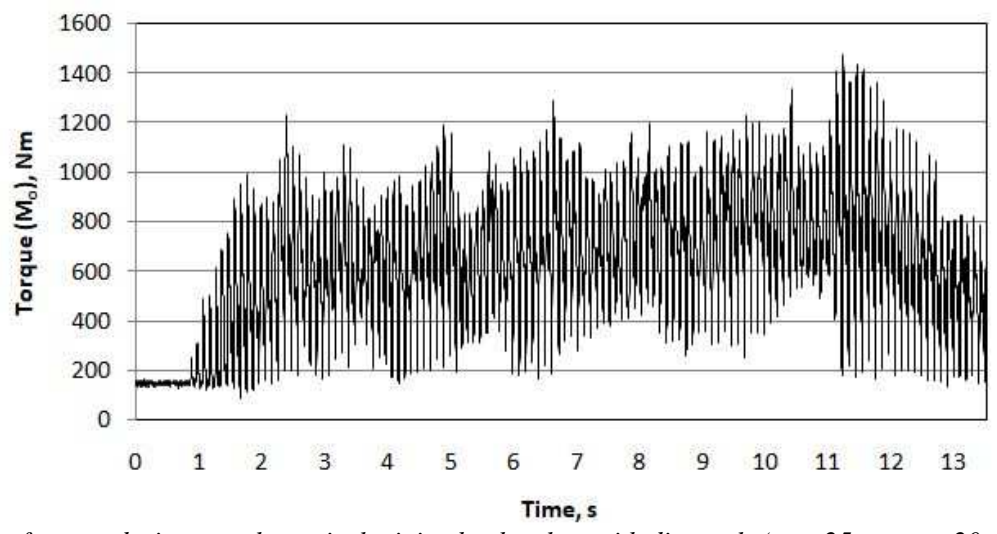

Fig.18. Graph of torque during sample vertical mining by the plate with disc tools ( $\left.g=25 \mathrm{~mm}, t=20 \mathrm{~mm}, v_{p}=0,05 \mathrm{~m} / \mathrm{s}\right)$

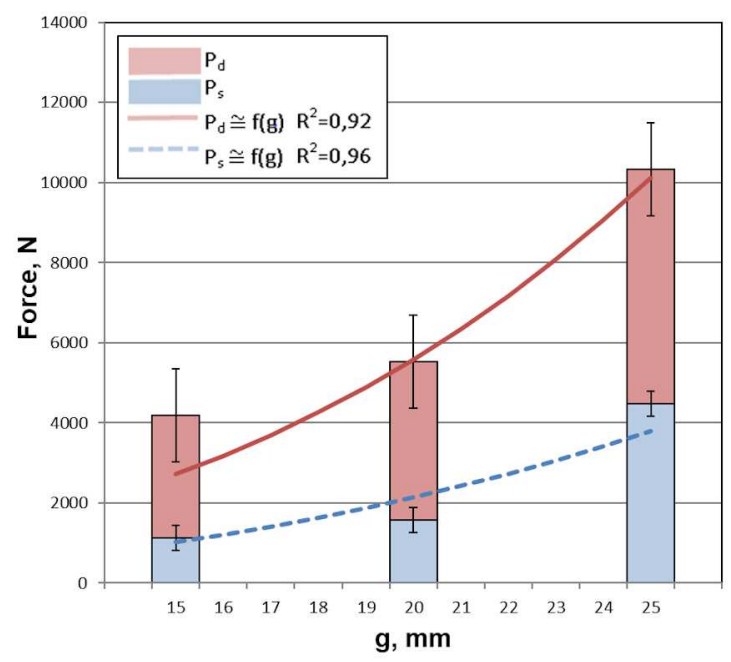

Fig.19. Mining forces as a result of the mining tests with the plate with disc tools $(t=20 \mathrm{~mm})$

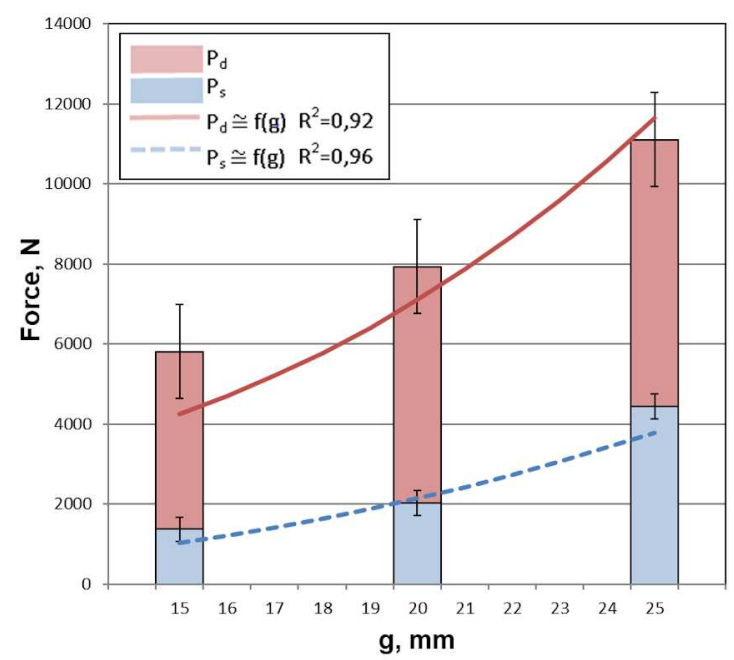

Fig.20. Mining forces as a result of the mining tests with the plate with disc tools $(t=40 \mathrm{~mm})$

\section{Selected aspects of the test results usefulness}

The conducted research significantly broadens the scope of knowledge in the field of mining with asymmetrical disc tools. The practical (utilitarian) aspect of described laboratory research out involves the use of test results for the selection of kinematic and dynamic parameters of a new type of roadheader disc head. The construction of such a head is shown in Fig. 21. The results of the research conducted on the prototype disc head confirmed the validity of the methodology used for testing with a single disc plate. In turn, the cognitive goal of the completed research was achieved by identifying the correlation between a number of geometrical parameters of disc and process tools and the values of mining resistance forces. Quantitative and qualitative assessment of the impact of selected independent variables on the formation of resistance to mining using asymmetrical disc tools is key information for the validation of analytical and simulation models of the mining process. An example simulation of pushing a disc tool into a rock sample is shown in Fig. $22\left(D=160 \mathrm{~mm}, t=25 \mathrm{~mm}, R_{c}=\right.$ $25 \mathrm{MPa}$ ).Taking into account the cost of manufacturing and researching prototype solutions of mining machines, it should be stated that the development of elementary models of rock cutting using asymmetrical discs will be an important factor determining the development of this type of construction. 


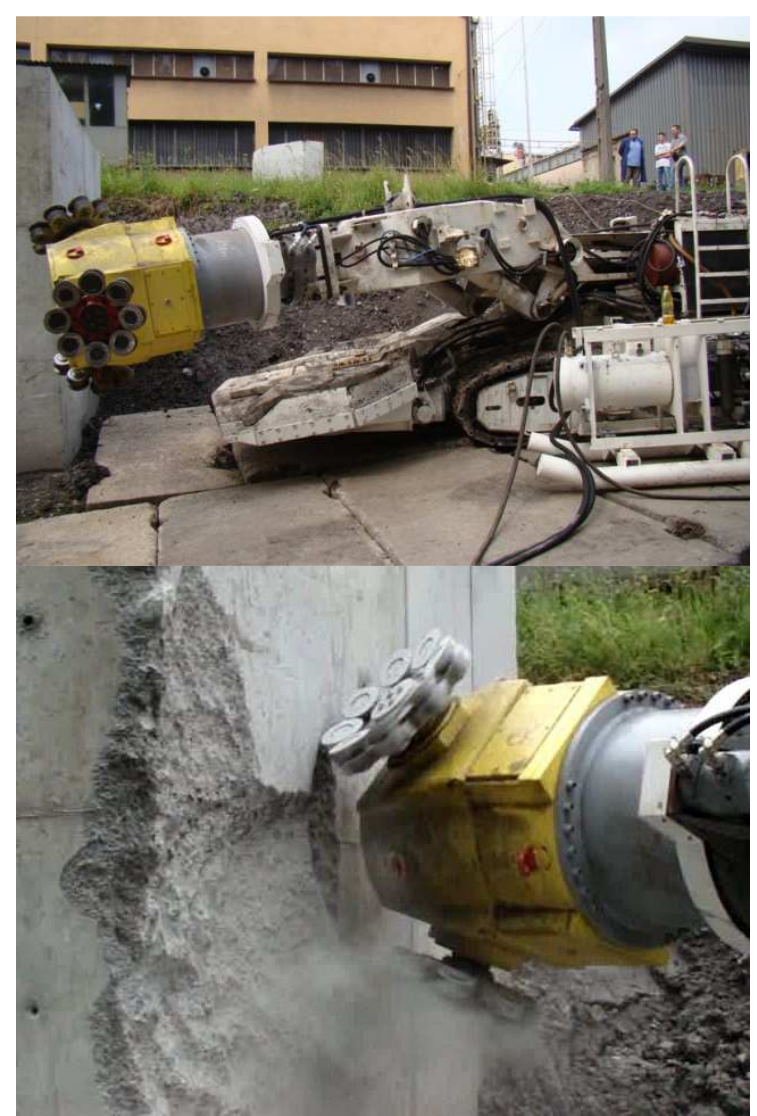

Fig.21. The new generation mining head with disc tools during field tests

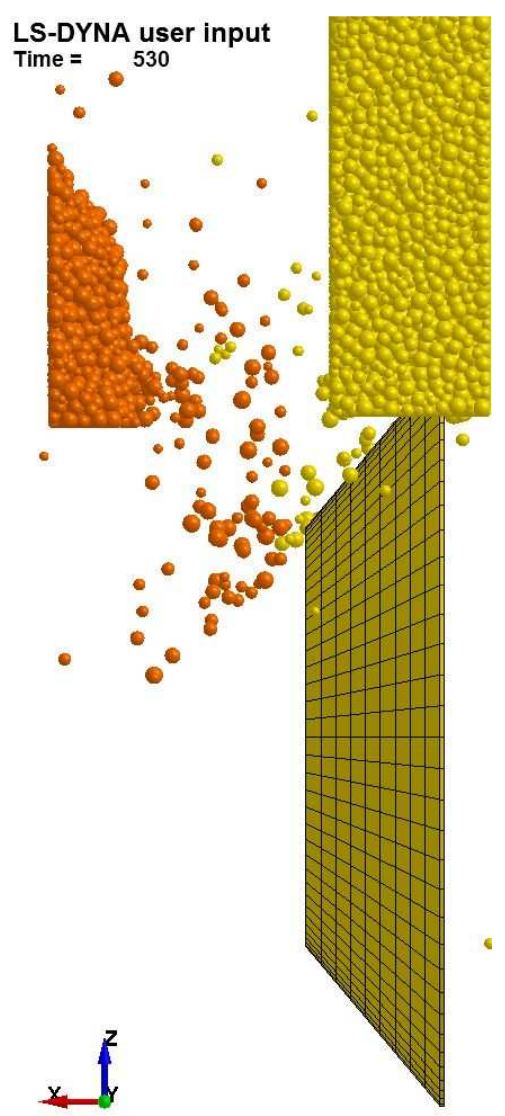

Fig.22. Simulation of rock cutting in LS-Dyna (Discrete Element Method)

\section{Conclusions}

The use of asymmetrical disc tools for the mining of hard and very hard rocks is a promising direction for the development of mechanical mining methods. Several industrial research has confirmed the possibilities of a significant reduction in the energy consumption of the mining process, and thus minimization of the size and weight of the mining machine (Biały, 2017). Also, research on the disc mining process that has been carried out so far confirmed the prospective character of the development of unconventional mining techniques based on disc tools.

One of the fundamental problems of application of asymmetrical disc tools in mining machine heads is the issues of forecasting their loads. Currently, there are no model foundations that would allow evaluating a load of disc tools, especially in the conditions of complex mining kinematics. The development of computer simulation tools gives hope for the development of efficient mining models due to the required accuracy and acceptable time-consumption of each test.

The results of laboratory tests presented in the described study constitute unique information regarding the impact of geometric parameters of disc tools and mining process parameters on the reaction force generated during mining. From a practical point of view, the presented test results can be input data for design purposes and can be used to select the necessary parameters of dynamic mining heads (Stopka, 2019). The relations between the individual geometric parameters of the discs and the mining process and the reaction forces, identified as a result of the conducted research, can be used to validate analytical and simulation mining models.

\section{References}

Acaroglu O., Erdogan, C. (2017). Stability analysis of roadheaders with mini-disc, Tunneling and Underground Space Technology, vol 68. s.187-195.

Asbury B., Ozdemir L. and Rostami J.(1998). Mini Disc Equipped Technology for Hard Rock Minig. SME 1998, Orlando, USA

Biały W. (2013). New devices used in determining and assessing mechanical characteristics of coal. 13th SGEM GeoConference on Science and Technologies in Geology, Exploration and Mining, SGEM2013 
Conference Proceedings, June 16-22, 2013, Vol. 1, BUŁGARIA ISBN 978-954-91818-7-6/ISSN 13142704. pp. 547-554.

Biały W. (2014). Coal cutting force measurement systems - (CCFM). 14th SGEM GeoConference on Science and Technologies In Geology. Exploration and Mining. SGEM2014 Conference Proceedings, Vol. III, pp. 91-98.

Biały W. (2017). Application of quality management tools for evaluating the failure frequency of cutter-loader and plough mining systems. Archives of Minning Sciences, Volume 62, issue 2, 2017. pp. 243-252. ISSN 0860-7001. DOI 10.1515/amsc-2017-0018.

Bołoz Ł. (2018). Model Tests of Longwall Shearer with String Feed System, Archives of Mining Sciences, 63(1), pp. 61-74.

Bołoz Ł., Leonel F. Castañeda (2018). Computer-aided support for the rapid creation of parametric models of milling units for longwall shearers, Management Systems in Production Engineering, 26(4), pp. 193-199.

Gajewski J., Podgórski J., Jonak J. and Szkudlarek Z. (2008). Numerical simulation of brittle rock loosening during mining process, Computational Materials Science, vol. 43.

Gospodarczyk P., Kotwica K. and Stopka G. (2013). A new generation mining head with disc tool of complex trajectory, Archives of Mining Sciences 2013 vol. 58 no. 4, s. 985-1006.

Gospodarczyk P, Kotwica K., Mendyka P. and Stopka G. (2016). Innovative roadheader mining head with asymmetrical disc tools, Exploration and mining, mineral processing. International Multidisciplinary Scientific GeoConference SGEM, vol.2, Sofia 2016, s. 489-496.

Gospodarczyk P., Kotwica K., Mendyka P. and Stopka G. (2015). Innovative solution of the roadheader mining head with disc tools of complex motion trajectory, Maschinen und Verfahren fur den Bergbau und Spezialtiefbau, Freiberg 2015/a, s. 53-63.

Gospodarczyk P., Mendyka P. and Stopka G. et al. (2015). Wybrane zagadnienia modelowania procesów urabiania, ładowania i odstawy w kompleksach ścianowych. Wydawnictwa AGH, Krakow 2015/b.

Huiyun Li, Erxia Du (2016). Simulation of rock fragmentation induced by a tunnel boring machine disk cutter, Advances in Mechanical Engineering, 2016, Vol. 8(6) 1-11

Kotwica K. (2003). Modelowanie urabiania skał zwięzłych narzędziami dyskowymi ze wspomaganiem wysokociśnieniowymi strugami wody. Archives of Mining Sciences, Vol. 43, Issue 1, 1998, s. 147 - 184

Kotwica K., Gospodarczyk P. (2003). Hard Rock Mining with use of New Cutting Tools. Journal of Mining Sciences. Vol. 39, No. 4 2003. s. 387-393.

Kotwica K. (2011). The influence of water assistance on the character and degree of wear of cutting tools applied in roadheaders. Archives of Mining Sciences. Vol. 56, 3/2011. s. 353-374

Kotwica K., Gospodarczyk P., Stopka G. and Kalukiewicz A. (2010). Projektowanie i badania stanowiskowe nowego rozwiązania głowicy z narzędziami dyskowymi o złożonej trajektorii ruchu do urabiania skał zwięzłych, Mechanics and Control, 3/2010

Labra C., Rojek J. and Oñate E. (2017). Discrete/Finite Element Modelling of Rock Cutting with a TBM Disc Cutte, Rock Mechanics and Rock Engineering, March 2017, Volume 50, Issue 3, pp 621-638

Manfred V. (2015). Maschinentechnische Herausforderung zur Umsetzung des Konzeptes Hinterschneidtechni, Symposium Tunnelbau, Zurich 2005.

Jonak J. and Podgórski J. (2012). Numeryczne badania skrawania skał anizotropowych dyskiem asymetrycznym, Politechnika Lubelska, 2012

Mendyka P. (2017). Laboratory stand tests of mining asymmetrical disc tools, Exploration and mining, mineral processing. International Multidisciplinary Scientific GeoConference SGEM, vol.17, Sofia 2017, s. 487494.

Stopka G. (2011). Badania procesu urabiania narzędziami dyskowymi. Doctoral Thesis. AGH w Krakowie, Kraków 2011.

Stopka G. (2019). Numerical simulation in design process of the new generation mining head with disc tools. Systemy Wspomagania w Inżynierii Produkcji: ISSN 2391-9361. - 2019 vol. 8 iss. 1 Górnictwo perspektywy i zagrożenia, s. 164-172.

Rojek J. (2007). Discrete element modeling of rock cutting, CompMethod Mater Sci 2007; 7: 224-230.

Roxborough F.F., Phillips H.R. (1975). Rock Excavation by Disc Cutter. Int. Journal of Rock Mech. and Min. Sci., Vol. 12, 1975.

Xiaohuo Li, Wei Du, Zhilong Huang and Weili Fu (2012). Simulation of Disc Cutter Loads Based on ANSYS/LS-DYNA, Applied Mechanics and Materials Vol. 127 (2012) pp 385-389

Xia Y.M., Guo B., Cong G.Q. and Zeng G.Y. (2017). Numerical simulation of rock fragmentation induced by a single TBM disc cutter close to a side free surface, International Journal of Rock Mechanics and Mining Sciences, Volume 91, January 2017, Pages 40-48 